\title{
Integrity, ethical leadership, trust and work engagement
}

\author{
Amos S. Engelbrecht, Gardielle Heine and Bright Mahembe
}

\begin{abstract}
Purpose - The purpose of this paper is to investigate how leader integrity and ethical leadership can influence trust in the leader and employee work engagement.

Design/methodology/approach - Data were collected using an electronic web-based questionnaire completed by 204 employees from various business organisations. Data were analysed by means of item analysis and confirmatory factor analysis conducted via structural equation modelling.

Findings - High levels of reliability were found for the measurement scales. Good model fit was demonstrated for the measurement and structural models. Empirical support was found for all the postulated relationships in the structural model.

Originality/value - This study is the first to analyse the joint relationships between leader integrity and work engagement through the mediating role of ethical leadership (i.e. moral management) and trust in the sise the key role played by ethical leaders in creating an ethical and trusting work climate conducive for employee engagement.
\end{abstract}

\section{Introduction}

Identifying the situations that foster work engagement of employees is vital for the sustainability and growth of organisations (Bakker and Demerouti, 2008; Den Hartog and Belschak, 2012; Tims et al., 2011). Engaged employees are more productive, enjoy their work, and are more efficient and involved in their work (Tims et al., 2011). One of the conditions that are critical in strengthening work engagement is organisational trust (Buckley, 2011). Because employees are more likely to engage in their work if they are drawn upon themselves to perform their roles, trust on the part of management is essential. Excessive monitoring and enforcement from management can hamper employees' tendency to engage in their work.

Ethical leadership is critical to a leader's credibility and his/her potential to exert meaningful influence (Den Hartog and Belschak, 2012). This credibility of ethical leaders is likely to have a significant influence on trust between a leader and followers (Eisenbeiss and Giessber, 2012).

Integrity, which refers to adherence to moral principles, captures the essence of ethical values and therefore can be seen as an important driver of ethical leadership (Palanski and Yammarino, 2011; Van Aswegen and Engelbrecht, 2009). One can also consider the impact 
integrity has on the concept of trust in that followers have confidence in leaders who are perceived as high on integrity (Schoorman et al., 2007).

\section{Conceptualisation of ethical leadership}

Researchers have begun to consider ethical leadership as a separate leadership style in itself rather than focusing only on the ethical elements of other leadership styles (e.g. transformational, authentic and servant leadership) (Brown et al., 2005; Kalshoven et al., 2011; Yukl et al., 2011).

Resick et al. (2006) empirically distinguished various dimensions of ethical leadership, such as character and integrity, altruism, motivating, encouraging and empowering. Kalshoven et al. (2011) identified similar dimensions, namely fairness, integrity, people orientation, role clarification, ethical guidance and power sharing. In line with these dimensions, Eisenbeiss (2012) identified a humane orientation and a justice orientation of ethical leadership.

The definition of ethical leadership by Brown et al. (2005) is widely used in the literature. Based on a qualitative study, Brown et al. (2005, p. 120) defined ethical leadership as "the demonstration of normatively appropriate conduct through personal actions and interpersonal relationships, and the promotion of such conduct to followers through twoway communication, reinforcement, and decision-making". The first part of this definition relates to the "moral person" facet of ethical leadership and the second part to the "moral manager" facet (Brown and Trevino, 2006).

Leaders embracing the moral person perspective value integrity and are trustworthy, caring, honest and fair. The moral manager or "ethical leadership" facet proactively manages morality, and it refers to a leader's efforts to influence subordinates and guide their ethical behaviour, such as communicating ethical standards and disciplining employees who demonstrate unethical behaviours. These behaviours further include making fair and principled decisions, acting as role models for ethical conduct and recognising and rewarding ethical behaviour. Mayer et al. (2012) consider the moral manager facet as most unique to the ethical leadership construct.

\section{Aim of the study}

Work engagement is the driver behind an organisation's competitiveness and success, in that an engaged employee demonstrates the willingness to put extra effort into the work and to reach optimal performance. Because the relationship between leaders and followers is so important in the company, trust and leadership are key aspects that should be considered, especially when it can contribute to the presence of employee work engagement. Ethical leadership is considered important, because, together with leader integrity, it promotes effective interaction between leaders and their followers. According to Brown and Trevino (2006), ethical leaders are perceived as honest and trustworthy, which is necessary for healthy working relationships.

The research objective of this study therefore was to make use of sound theoretical research and logical reasoning to analyse the influence of leader integrity and ethical leadership on 
trust in the leader and work engagement. The further aim was to validate a theoretical model explicating the structural relationships between these variables in the business context.

No study could be found that has examined leader integrity (i.e. moral person) as an antecedent of ethical leadership (i.e. moral management). According to Stouten et al. (2012), future research should determine whether moral persons and moral managers are truly perceived as such by subordinates and whether they will respond differently as a result of this. The theoretical model of this study posits that integrity motivates leaders to act in ways that demonstrate ethical behaviour. Consequences of ethical leadership were also explored, particularly trust in the leader and work engagement. No study could be found that has analysed the relationship between ethical leadership and these outcomes. This study aimed to address these gaps in the management literature.

\section{The relationship between trust in leader and work engagement}

Work engagement is present when an employee is fully committed to the work through focussed energy and a positive state of mind (Tims et al., 2011). Trust in the leader can be defined as the employee $s$ willingness to accept vulnerability on the basis of positive expectations of the intentions of the leader (Schoorman et al., 2007).

Social exchange relationships depend upon trust, feelings of personal obligation and norms of reciprocity (Blau, 1964). The subordinates of ethical leaders are likely to perceive themselves as being in social exchange relationships with their leaders because of the trust they feel in their leaders (Brown and Trevino, 2006). As a result, the subordinates should be inclined to go above and beyond the call of duty for these leaders through their job dedication (Kalshoven et al., 2011) and work engagement.

In a study that was done on the effect of downsizing on trust in the organisation, it was found that employees who experience an increase in trust also experience an increase in work engagement (Buckley, 2011). Wong et al. (2010) through their study confirmed that trust has a direct positive effect on work engagement. They indicated that increased trust includes the free exchange of knowledge, ideas and information and that this trust will lead to a climate in which employees are actively engaged in their work.

From the above assumptions and findings, the following can be postulated:

H1. Trust in the leader has a significantly positive influence on the follower's work engagement.

\section{The relationship between ethical leadership and work engagement}

When employees are treated in a fair and respectful way by their leaders, they are likely to think about their relationship with their leader in terms of social exchange (Blau, 1964) rather than economic exchange. Furthermore, they are likely to reciprocate by putting extra effort into their work, through enhanced job dedication (Brown et al., 2005) and willing to become more actively engaged in work (Macey et al., 2009). 
When an employee has the freedom to make decisions and take action without consulting the supervisor all the time, it can result in work engagement (Macey et al., 2009). Bellingham (2003) states that ethical leaders want to empower employees through training and support and they want to provide freedom to their employees to show initiative through responsibility and authority.

Ethical leaders take their followers into consideration and through open communication (Brown and Trevino, 2006) make it clear what the organisation's goals are and what is expected from subordinates, which leads to employee engagement in their work (Macey et al., 2009).

Brown et al. (2005) found a positive correlation between ethical leadership and job dedication, which is a major element of work engagement (Schaufeli and Bakker, 2003).

Through regression analysis, Den Hartog and Belschak (2012) confirmed that ethical leadership has a positive relationship with work engagement. They found that followers tend to report higher engagement in their work when they perceive their leaders as acting ethically. Consequently, the following can be postulated:

H2. Ethical leadership has a significantly positive influence on the follower's work engagement.

\section{The relationship between ethical leadership and trust in the leader}

Social exchange theory suggests that trust grows as leaders and subordinates interact in highquality relationships (Blau, 1964). Ethical leaders' fair and caring treatment and open communication signal trust that subordinates are likely to reciprocate.

An ethical leader's concern for the best interests of subordinates, openness to input, fair decision making and actively managing morality should result in the leader's attractiveness as a role model. The treating people fairly element of ethical leadership would particularly enhance the experiencing of ethical leaders as trustworthy by their subordinates (Brown et al., 2005; Eisenbeiss, 2012).

Dadhich and Bhal (2008) found that affective trust and cognitive trust are predicted by ethical leadership. Brown et al. (2005) as well as Van den Akker et al. (2009) found that ethical leadership is significantly related to the level of trust the follower has in the leader. In addition, Johnson et al. (2012) reported a positive relationship between ethical leadership and organisational trust. Kalshoven et al. (2011) found that ethical leader behaviours, measured with the ELW as well as the ELS (Brown et al., 2005), were positively correlated with trust in manager/leader. Therefore, the following can be postulated:

H3. Ethical leadership has a significantly positive influence on the trust in the leader.

\section{The relationship between leader integrity and trust in the leader}

Yukl (2013, p. 331) refers to integrity as "honesty and consistency between a person's espoused values and behaviour". Drawing on social exchange, trust in leaders is built on ethical leaders' behaviours such as integrity, and reliability behaviour, which likely result in 
trust that subordinates may reciprocate. Thus, based on social learning theory, subordinates will be inclined to trust ethical leaders because of their role modelling behaviour demonstrated through their credibility and trustworthiness. Ethical leaders also have the courage to transform their moral intentions into ethical behaviours, which can be referred to as a high behavioural consistency (Zhu et al., 2004). When employees perceive this consistency, followers' trust in the leader is likely to increase.

According to Colquitt et al. (2007), integrity offers a very logical reason to trust someone. A feeling of fairness or moral character provides a sort of predictability that can help individuals cope with uncertainty. A leader with integrity will therefore be perceived as trustworthy, which will lead to trust in that leader.

Mayer and Gavin (2005) reported integrity as positively related to trust in the plant manager and in the top management team. Both Palanski and Yammarino (2011) and Kannan-Narasimhan and Lawrence (2012) found that leader behavioural integrity has a positive impact on followers' trust in the leader. Engelbrecht and Cloete (2000) also reported a positive relationship between integrity and interpersonal trust. Furthermore, Kalshoven et al. (2011) found a positive correlation between integrity and trust in the manager/leader. Therefore, the following can be postulated:

H4. Leader integrity has a significantly positive influence on the trust in the leader.

\section{The relationship between leader integrity and ethical leadership}

Brown and Trevino (2006) reported that leader traits such as honesty, integrity and trustworthiness contributed to the "moral person" facet of ethical leadership. Mayer et al. (2012) showed that an ethical leader's personal values (e.g. integrity and altruism) are an integral part of their social identity and help them to be a moral person. Integrity shows some conceptual overlap with ethical leadership, yet is only one facet of ethical behaviour (Palanski and Yammarino, 2007). Research by Mayer et al. (2012) shows that leader's ethical behaviour flows from the leader' own personal moral values.

Integrity and honesty should be crucial to the legitimacy and attractiveness of a role model (Bandura, 1986) and has frequently been linked with ethical leadership (Brown and Trevino, 2006). However, because ethical leadership encompasses more than truth-telling, Brown et al. (2005) assert that honesty and ethical leadership will be positively related but be empirically distinguishable from one another.

Brown et al. (2005) propose that integrity is the foundation of ethical leadership. Integrity can therefore be described as a component of ethical leadership, but the concept of integrity is such a comprehensive construct that it in itself also has an important impact on ethical leadership. The focus of ethical leadership is on the management of ethics.

If a person is rated highly on integrity, he/she will show personal consistency in behaviour which is based on moral values (Palanski and Yammarino, 2007). This characteristic of 
integrity will be a significant driver for the person to engage in ethical leadership in an attempt to influence followers.

Brown et al. (2005) found a positive correlation between leader honesty and ethical leadership. Kalshoven et al. (2011) found a positive correlation between integrity and ethical leadership measured with the ELS (Brown et al., 2005). Consequently, the following can be postulated:

H5. Leader integrity has a significantly positive influence on ethical leadership.

\section{Conceptual model}

Based on the in-depth literature review and theoretical arguments presented above, a structural model was formulated showing the postulated relationships between leader integrity, ethical leadership, trust in the leader and work engagement. The structural model, illustrated in Figure 1, reflects the various paths and linkages between the different latent variables. It is clear from Figure 1 that integrity would be a significant driving force for a person to engage in ethical leadership in an attempt to influence followers (Brown et al., 2005; Kalshoven et al., 2011; Mayer et al., 2012; Palanski and Yammarino, 2007). A leader with integrity would be perceived as trustworthy, which will lead to trust in the leader (Colquitt et al., 2007; Kalshoven et al., 2011; Kannan-Narasimhan and Lawrence, 2012; Mayer and Gavin, 2005; Palanski and Yammarino, 2011). An ethical leader's concern for the best interests of subordinates, openness to input and fair decision making would enhance the experiencing of ethical leaders as trustworthy by their subordinates (Dadhich and Bhal, 2008; Eisenbeiss, 2012; Johnson et al., 2012; Kalshoven et al., 2011; Van den Akker et al., 2009). Ethical leaders want to empower employees through training and support, and they want to provide freedom to their employees to show initiative through responsibility and authority, which leads to employee engagement in their work (Den Hartog and Belschak, 2012; Macey et al., 2009). When the employees perceive the leaders as fair in the distribution of rewards and treatment of their efforts, trust in the leaders will increase that would lead to a climate in which employees are engaged in their work (Buckley, 2011; Wong et al., 2010).

\section{Method}

\section{Participants}

This study uses non-probability convenience sampling as a way of obtaining the sample. The research hypotheses were empirically tested using a sample size of 204 respondents which consisted of employees operating within various organisations in South Africa. The sample consisted of 123 females (6o.3 per cent) and presented with an average age of 37.53 years. The race distribution was as follows: African (5.4 per cent), coloured (2 per cent), Indian (34.8 per cent) and white ( 57.8 per cent). The majority of respondents were from middlelevel management (58.3 per cent) and from the retail industry (80.4 per cent). 
Figure 1.

The structural model

representing the

relationships between

integrity, ethical

leadership, trust and

work engagement

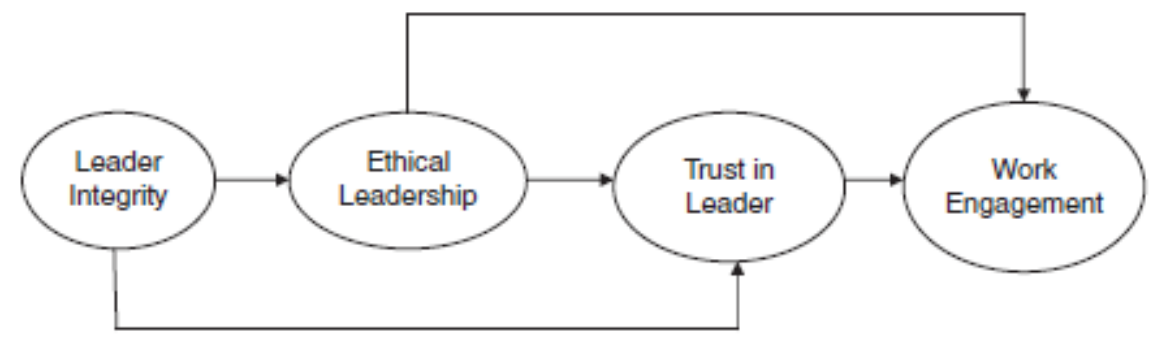

\section{Measures}

Work engagement was measured by the 17-item Utrecht Work Engagement Scale (UWES). The UWES developed by Schaufeli and Bakker (2003) contains three dimensions of work engagement, namely vigour, dedication and absorption. The UWES has demonstrated sound psychometric properties where the three-factor structure of the UWES fits well in the data of various samples and therefore confirms factorial validity. The three scales are highly internally consistent, with Cronbach's a values exceeding 0.70 (Schaufeli and Bakker, 2003). Sample items included the following: "At my work, I feel bursting with energy"; "I am enthusiastic about my job"; and "When I am working, I forget everything else around me".

Trust in the leader was measured by the 13-item Leader Trust Scale (LTS), adapted from the trust instrument developed by Bews (2000) and the Workplace Trust Survey developed by Ferres et al. (2004). Sample items included the following: "I feel that my manager keeps personal discussions confidential" and "I can depend on my manager".

Ethical leadership was measured by the 17-item Leadership of Ethics Scale (LES), which was specifically developed to measure the moral manager aspect of ethical leadership (Brown et al., 2005). The LES items were adapted from different measures of ethical leadership (Brown et al., 2005; Spangenberg and Theron, 2005; Yukl et al., 2011). The LES combines different leader behaviours such as acting fairly, rewarding ethical conduct, ethical visioning and ethical practices of ethical leaders. Sample items included the following: "My manager communicates an ethical vision and inspires subordinate commitment to the vision" and "My manager recognises and rewards ethical contributions and behaviour".

Leader integrity was measured by the nine-item Behavioural Integrity Survey (BIS), specifically developed to measure the moral person dimension of ethical leadership (Brown et al., 2005). The BIS was designed to measure the word-action consistency, promise fulfilment and honesty/morality dimensions of integrity (Palanski and Yammarino, 2007; Simons et al., 2007). Sample items included the following: My manager always tells me the truth" and "My manager shows a strong concern for moral values".

\section{Results}

\section{Reliability analysis}

SPSS (Version 20) was used to perform item analysis on all four measurement scales. After examination of all the scales, it was concluded that all the Cronbach's a values exceeded the 
required 0.70 cut-off value, and all items presented high item-total correlations (see Table I). Each scale was therefore considered to be internally consistent and reliable.

\section{Evaluating the measurement models}

LISREL 8.80 ( Jöreskog and Sörbom, 2006) was used to perform confirmatory factor analysis on all the scales used in this study.

\begin{tabular}{lccccc}
\hline Scale & Number of items & Mean $^{\mathrm{a}}$ & $\mathrm{SD}$ & Cronbach's $\alpha$ & Item-total correlation \\
\hline UWES: absorption & 6 & 28.95 & 5.65 & 0.89 & $0.62-0.80$ \\
UWES: dedication & 5 & 25.10 & 4.86 & 0.91 & $0.69-0.88$ \\
UWES: vigour & 6 & 29.47 & 4.99 & 0.88 & $0.61-0.78$ \\
LTS & 13 & 68.48 & 11.54 & 0.97 & $0.71-0.89$ \\
LES & 17 & 85.87 & 14.71 & 0.97 & $0.63-0.88$ \\
BIS & 9 & 46.36 & 8.34 & 0.96 & $0.69-0.90$
\end{tabular}

Notes: UWES, Utrecht Work Engagement Scale; LTS, Leader Trust Scale; LES, Leadership of Ethics Scale; BIS, Behavioural Integrity Survey. ${ }^{\text {Based on total scores }}$

Table I.

Reliability of the measurement scales

The modification indices were investigated to determine the possibility of deleting items with lower loadings on the completely standardised solution matrix. From the UWES, a poor item from the absorption subscale and one from the vigour subscale were removed in order to increase the model fit. All items included in the LTS loaded satisfactorily (W 0.50) on the latent variable. Three items of the LES and one item of the BIS were deleted because of their lower factor loadings. The deletion of these items resulted in an improvement in the fit indices.

The final step in the analysis of the measurement models was to test the fit of each measurement model in terms of goodness-of-fit statistics. The fit indices of the refined subscales of the UWES are represented in Table II.

The fit indices indicate that the measurement models of absorption, dedication and vigour present acceptable fit with the data. The RMSEA suggests that the refined measurement models fit the obtained data adequately (0.00-0.055) (Hair et al., 2006; Kelloway, 1998). The $p$-value for Test of Close Fit (RMSEA O 0.05) ranges from 0.38 to 0.69 ( $p \mathrm{~W}$ 0.05), supporting the conclusion that the various measurement models show close fit. The RMR and standardised RMR values are all below the 0.05 threshold, providing evidence of a relatively good model fit (Diamantopoulos and Siguaw, 2000; Hair et al., 2006). The GFI for each of the measurement models are close to 1 and above 0.90 . This indicates that good absolute fit has been achieved for each measurement model (Kelloway, 1998).

The results of the incremental fit indices indicate that all the measurement models achieve NFI and CFI indices that are W 0.90, which represents good fit (Hair et al., 2006). These comparative indices therefore, appear to reveal a positive picture of model fit.

Overall, the reported indices indicate that satisfactory measurement model fit was also achieved for the LTS, LES and BIS measurement models (see Table II). 


\section{Evaluating the structural model}

An interpretation of all the fit indices led to the conclusion that the structural model fitted the data well (see Table II). Only the GFI did not indicate good fit.

Examination of the modification indices suggested that there were no additional paths between any latent variables that would significantly improve the fit of the proposed structural model. These results therefore indicated that the structural model was successful to the extent that it explained the observed covariance amongst the apparent variables.

\section{Discussion}

\section{The relationship between trust in leader and work engagement}

A positive relationship was found between trust in the leader and employee engagement $(t=2.33$, poo.05) (see Table III). The structural equation modelling results led to the rejection of null $H 1$. The finding is consistent with the results obtained in the literature (Buckley, 2011; Wong et al., 2010).

Table II.

Goodness-of-fit indices for all the scales and subscales

\begin{tabular}{lcrlcccccc}
\hline Model & S-B $\chi^{2}$ & df & RMSEA & $p_{\text {close fit }}$ & RMR & SRMR & GFI & NFI & CFI \\
\hline Absorption & 4.791 & 5 & 0.00 & 0.69 & 0.03 & 0.02 & 0.99 & 0.99 & 0.99 \\
Dedication & 6.950 & 5 & 0.044 & 0.48 & 0.03 & 0.02 & 0.98 & 0.99 & 0.99 \\
Vigour & 8.044 & 5 & 0.055 & 0.38 & 0.03 & 0.03 & 0.98 & 0.99 & 0.99 \\
LTS & $124.865^{*}$ & 65 & 0.067 & 0.06 & 0.03 & 0.03 & 0.86 & 0.98 & 0.99 \\
LES & $146.103^{*}$ & 77 & 0.067 & 0.052 & 0.04 & 0.04 & 0.87 & 0.98 & 0.99 \\
BIS & $37.558^{*}$ & 20 & 0.066 & 0.195 & 0.03 & 0.03 & 0.93 & 0.99 & 0.99 \\
SMODEL & $1,877.089^{*}$ & 1,170 & 0.055 & 0.052 & 0.06 & 0.05 & 0.68 & 0.97 & 0.99
\end{tabular}

Notes: S-B $\chi^{2}$, Sattora-Bentler Scaled $\chi^{2}$; df, Degrees of freedom; RMSEA, Root-mean-square error of approximation; $p_{\text {close fit }} p$-value for Test of Close Fit (RMSEA < 0.05); RMR, Root-mean-square residual; SRMR, Standardised root mean residual; GFI, Goodness-of-fit index; NFI, Normed fit index; CFI, Comparative fit index; LTS, Leader trust scale; LES, Leadership of Ethics Scale; BIS, Behavioural Integrity Survey; SMODEL, structural model. $* p<0.05$

\begin{tabular}{|c|c|c|c|c|}
\hline Latent variable & Ethical leadership & Trust & Integrity & Einics, trust \\
\hline Trust & $\begin{array}{c}0.52 \\
(0.10) \\
5.01^{*}\end{array}$ & & $\begin{array}{c}0.43 \\
(0.09) \\
4.60^{*}\end{array}$ & engagement \\
\hline Work engagement & $\begin{array}{c}0.31 \\
(0.14) \\
2.27^{*}\end{array}$ & $\begin{array}{c}0.32 \\
(0.14) \\
2.33^{*}\end{array}$ & & 375 \\
\hline $\begin{array}{l}\text { Notes: Completely } \\
t \text {-values } \geqslant|1.96| \text { ind }\end{array}$ & $\begin{array}{l}\text { path coefficients } \\
\text { t parameter estimate }\end{array}$ & ard error & $\begin{array}{c}0.85 \\
(0.11) \\
7.90^{*} \\
\text { brackets; }\end{array}$ & $\begin{array}{r}\text { Table III. } \\
\text { The } \gamma \text { and } \beta \text { matrix } \\
\text { of path coefficients for } \\
\text { the structural model }\end{array}$ \\
\hline
\end{tabular}

The results support the study by Wong et al. (2010), which found that a climate in which employees are engaged in their work can be created through the trustworthy behaviours of the leader. If employees trust their leader, they assume that the leader will make decisions with the employees' best interest in mind, and the employees will be more willing to engage in their jobs (Buckley, 2011). 
It was confirmed in the present study that a relationship expressive of trust in the leader will promote the presence of employee engagement; the employee will be driven and committed to the work on the basis of the trust he/she has in the leader to make informed and fair decisions regarding the work.

\section{The relationship between ethical leadership and work engagement}

Support was found in the present study for a positive relationship between ethical leadership and follower's work engagement $(t=2.27, p$ o 0.05) (see Table III). This subsequently led to the confirmation of $\mathrm{H} 2$.

This result offers support to similar research findings in the literature (Brown et al., 2005; Den Hartog and Belschak, 2012; Macey et al., 2009). The positive relationship sustains the work of Den Hartog and Belschak (2012) who found that followers are highly engaged in their work when they perceive their leaders as acting ethically.

Leaders who promote ethical behaviour empower employees by providing them with the necessary opportunities to become capable in executing their jobs. Ethical leaders treat employees equally and promote fair and principled decision making. They communicate openly to their followers about goals and expectations (Brown and Trevino, 2006). Ethical leaders inspire employees through an ethical vision and provide the freedom to employees to take initiative in the workplace. These behaviours of an ethical leader provide the environment and the opportunity for the employees to be fully engaged in their work.

\section{The relationship between ethical leadership and trust in the leader}

The hypothesised relationship between ethical leadership and trust in the leader was confirmed in this study ( $t=5.01, p$ o0.05) (see Table III), which supported H3. The positive relationship between these two latent variables is also well documented in the literature (Brown and Trevino, 2006; Dadhich and Bhal, 2008; Johnson et al., 2012; Kalshoven et al., 2011; Van den Akker et al., 2009; Wong et al., 2010).

The degree to which the leader is perceived as trustworthy will influence the way in which the follower places his/her confidence, trust and belief in the leader. A leader who values ethics and manages ethics in the workplace is likely to display fairness and care towards the employees (Brown and Trevino, 2006).

An ethical leader is dedicated to open communication and to involving others in decisions (Brown and Trevino, 2006). These behaviours of an ethical leaders are concurrent with leaders who are trusted by their followers.

When an employee perceives his/her leader as someone with concern for ethical behaviour and who will take employees' needs into consideration when important decisions are made, he or she will be likely to display sincere trust in the leader (Wong et al., 2010). 


\section{The relationship between leader integrity and trust in the leader}

A positive relationship was found between leader integrity and trust in the leader $(t=$ 4.60, poo.05) (see Table III). Alternative $H_{4}$ was therefore supported. Various other studies have also confirmed the positive relationship between these two constructs (Engelbrecht and Cloete, 2000; Kalshoven et al., 2011; Kannan-Narasimhan and Lawrence, 2012; Mayer and Gavin, 2005; Palanski and Yammarino, 2011; Schoorman et al., 2007; Simons, 2002).

Trust is widely associated with moral behaviour, such as exhibited in fairness, consistency, benevolence and integrity (Colquitt et al., 2007; Schoorman et al., 2007). As mentioned previously, integrity is associated with consistent and reliable behaviour, which is based on moral standards. A leader with integrity is therefore also perceived as trustworthy, which will strengthen the trust in that leader.

This study confirmed Simons' (2002) argument that behavioural integrity has a strong influence on trust in the leader. A leader who actively demonstrates integrity through honesty, consistency and moral behaviour will be successful in establishing trust in the leader/subordinate relationship.

\section{The relationship between leader integrity and ethical leadership}

A positive relationship was found between leader integrity and ethical leadership ( $t=7.90$, poo.05) (see Table III). This subsequently led to the rejection of null $H_{5}$. This result supported the positive relationship between these variables found by Kalshoven et al. (2011).

Palanski and Yammarino (2007) proposed that a person with integrity will demonstrate behaviours that are based on moral values. The fact that integrity is part of the moral value drive behind ethical leadership may support the assumption that a leader with integrity will be encouraged to engage in ethical behaviour in an attempt to influence followers (Den Hartog and Belschak, 2012).

A leader who values ethics and manages ethics in the workplace is likely to display honesty, fairness and care towards the employees (Brown and Trevino, 2006; Van Aswegen and Engelbrecht, 2009). Behavioural integrity can therefore have a considerable effect on a leader who is dedicated to the management of ethics in the workplace.

\section{Limitations of the study and suggestions for future research}

Although this study offers valuableinsights about the consequences of ethical leadership, some limitations need to be considered for the purpose of providing information on how future studies can be improved and extended. First, this study was a single-source study. Multiple sources of data could be considered in future studies, such as leader self-assessments of their ownintegrity and ethical leadership, and peer ratings.

Second, future studies could explore other mediating and moderating variables (e.g. integrityrelated personality traits, altruism, psychological empowerment, ethical climate and organisational justice) to clarify the nomological network that may influence ethical leadership and work engagement. It 
is also suggested that a longitudinal study of the proposed conceptual model should be executed to enable more substantial causal inferences.

A third limitation concerns the sampling method that was used. It is suggested, therefore, that future studies should avoid making use of a convenient sample, but could make use of a quota sampling technique. Future studies should also make use of a larger sample chosen on the basis of greater probability and randomness. This will ensure that the sample is more representative of the general business population.

\section{Managerial implications}

As confirmed through this study, mutual trust and employee engagement will strengthen when integrity behaviour and ethical leadership are present in the work environment. The good fit indices of the measurement models confirmed the postulation that moral persons and moral managers are perceived as such by subordinates (Stouten et al., 2012). As stated by Brown et al. (2005), it remains important to be a moral manager, not just a moral person, through implementing moral values and an ethical vision, making it visible by living it out in the organisation. Practical guidelines therefore would suggest leading through ethical role modelling, developing performance criteria that reward ethical behaviour, facilitating fair and ethical solutions to problems and conflict, monitoring fraud and corruption through internal and external audit systems and promoting a code of ethical conduct (Yukl, 2013). To prepare managerial leaders for dealing with typical moral challenges and dilemmas, training programmes should be developed aimed to create ethical awareness and to develop managers' capacity to find morally justifiable solutions by using interactive learning techniques (e.g. case studies, role play and coaching).

\section{Conclusion}

Organisations should take full responsibility for ensuring that ethical leaders drive management practices and that trust in the leaders is developed through the presence of ethically based business systems and functions. By strengthening these factors, work engagement is promoted amongst employees because of the trust they have in their leaders for taking their interests into consideration, and for behaving in a fair and ethical manner when decisions are made in a changing work environment. 


\section{References}

"Towards a model of work engagement", Career Development International, Vol. 13 No. 3, pp. 209-223.

Bandura, A. (1986), Social Foundations of Thought and Action, Prentice-Hall, Englewood Cliffs, NJ. Bellingham, R. (2003), Ethical Leadership: Rebuilding Trust in Corporations, HRD Press, Amherst, MA.

Bews, N.F. (2000), "An investigation into the facilitators of the trustworthiness of managers", Unpublished doctoral thesis, Rand Afrikaans University, Johannesburg.

Blau, P. (1964), Exchange and Power in Social Life, Wiley \& Sons, New York, NY.

Brown, M.E. and Trevino, L.K. (2006), "Ethical leadership: a review and future directions", The Leadership Quarterly, Vol. 17 No. 6, pp. 595-616.

Brown, M.E., Trevino, L.K. and Harrison, D. (2005), "Ethical leadership: a social learning perspective for construct development and testing", Organisational Behaviour and Human Decision Processes, Vol. 97 No. 2, pp. 117-134.

Buckley, F. (2011), "Trust and engagement in a downsizing context: the impact on human resource managers", in Searle, R.H. and Skinner, D. (Eds), Trust and Human Resource Management, 1st ed., Edward Elgar, Cheltenham, pp. 309-329.

Colquitt, J.A., Scott, B.A. and LePine, J.A. (2007), "Trust, trustworthiness, and trust propensity: a meta-analytic test of their unique relationships with risk taking and job performance", Journal of Applied Psychology, Vol. 92 No. 4, pp. 909-927.

Dadhich, A. and Bhal, K.T. (2008), "Ethical leader behaviour and leader-member exchange as predictors of subordinate behaviours", Vikalpa, Vol. 33 No. 4, pp. 15-25.

Den Hartog, D.N. and Belschak, F.D. (2012), "Work engagement and machiavellianism in the ethical leadership process", Journal of Business Ethics, Vol. 107 No. 1, pp. 35-47.

Diamantopoulos, A. and Siguaw, J.A. (2000), Introducing LISREL: A Guide for the Uninitiated, Sage, London. Eisenbeiss, S.A. (2012), "Re-thinking ethical leadership: an interdisciplinary integrative approach", The Leadership Quarterly, Vol. 23 No. 5, pp. 791-808.

Eisenbeiss, S.A. and Giessber, S.R. (2012), "The emergence and maintenance of ethical leadership in organizations: a question of embeddedness?”, Journal of Personnel Psychology, Vol. 11 No. 1, pp. 7-19.

Engelbrecht, A.S. and Cloete, B.E. (2000), "An analysis of a supervisor-subordinate trust relationship”, Journal of Industrial Psychology, Vol. 26 No. 1, pp. 24-28.

Ferres, N., Connell, J. and Travaglione, A. (2004), "Co-worker trust as a social catalyst for constructive employees attitudes”, Journal of Managerial Psychology, Vol. 19 No. 6, pp. 608-622.

Hair, J.F., Black, W.C., Babin, B.J., Anderson, R.E. and Tatham, R.L. (2006), Multivariate Data Analysis, 6th ed., Prentice Hall, Upper Saddle River, NJ.

Johnson, C.E., Shelton, P.M. and Yates, L. (2012), "Nice guys (and gals) finish first: ethical leadership and organizational trust, satisfaction and effectiveness", International Leadership Journal, Vol. 4 No. 1, pp. 3-19.

Jöreskog, K.G. and Sörbom, D. (2006), LISREL 8: User's Reference Guide, Scientific Software International, Inc., Chicago, IL. 
Kalshoven, K., Den Hartog, D.N. and De Hoogh, A.H.B. (2011), "Ethical leadership at work questionnaire (ELW): development and validation of a multidimensional measure", The Leadership Quarterly, Vol. 22 No. 1, pp. 51-69.

Kannan-Narasimhan, R. and Lawrence, B.S. (2012), "Behavioural integrity: how leader referents and trust matter to workplace outcomes", Journal of Business Ethics, Vol. 111 No. 2, pp. 165-178.

Kelloway, E.K. (1998), Using LISREL for Structural Equation Modeling: A Researcher's Guide, SAGE, Thousand Oaks, CA.

Macey, W.H., Schneider, B., Barbera, K.M. and Young, S.A. (2009), Employee Engagement: Tools for Analysis, Practice and Competitive Advantage, Wiley-Blackwell, Oxford.

Mayer, D.M., Aquino, K., Greenbaum, R.L. and Kuenzi, M. (2012), "Who displays ethical leadership, and why does it matter? An examination of antecedents and consequences of ethical leadership", Academy of Management Journal, Vol. 55 No. 1, pp. 151-171.

Mayer, R.C. and Gavin, M.B. (2005), "Trust in management and performance: who minds the shop while the employees watch the boss?”, Academy of Management Journal, Vol. 48 No. 5, pp. 874-888.

Palanski, M.E. and Yammarino, F.J. (2007), "Integrity and leadership: clearing the conceptual confusion”, European Management Journal, Vol. 25 No. 3, pp. 171-184.

Palanski, M.E. and Yammarino, F.J. (2011), "Impact of behavioural integrity on follower job performance: a three-study examination”, The Leadership Quarterly, Vol. 22 No. 1, pp. 765-786.

Resick, C.J., Hanges, P.J., Dickson, M.W. and Mitchelson, J.K. (2006), "A cross-cultural examination of the endorsement of ethical leadership", Journal of Business Ethics, Vol. 63 No. 4, pp. 345-359.

Schaufeli, W. and Bakker, A. (2003), Utrecht Work Engagement Scale Preliminary Manual, Occupational Health Psychology Unit, Utrecht University, Utrecht.

Schoorman, F.D., Mayer, R.C. and Davis, J.H. (2007), "An integrative model of organizational trust: past, present and future", Academy of Management Review, Vol. 32 No. 2, pp. 344354 .

Simons, T. (2002), "Behavioural integrity: the perceived alignment between managers' word and deeds as a research focus", Organizational Science, Vol. 13 No. 1, pp. 18-35.

Simons, T., Friedman, R., Lui, L.A. and Parks, J.M. (2007), "Racial differences in sensitivity to behavioural integrity: attitudinal consequences, in-group effects, and 'trickle down' among black and non-black employees”, Journal of Applied Psychology, Vol. 92 No. 3, pp. 650-665.

Spangenberg, H. and Theron, C.C. (2005), "Promoting ethical follower behaviour through leadership of ethics: the development of the ethical leadership inventory (ELI)", South African Journal of Business Management, Vol. 36 No. 2, pp.1-18.

Stouten, J., Van Dijke, M. and De Cremer, D. (2012), "Ethical leadership: an overview and future perspectives", Journal of Personnel Psychology, Vol. 11 No. 1, pp. 1-6.

Tims, M., Bakker, A.B. and Xanthopoulou, D. (2011), "Do transformational leaders enhance their followers' daily work engagement?”, The Leadership Quarterly, Vol. 22 No. 1, pp. 121-131. 
Van Aswegen, A.S. and Engelbrecht, A.S. (2009), "The relationship between transformational leadership, integrity and an ethical climate in organisations", $S A$ Journal of Human Resource Management, Vol. 7 No. 1, pp. 221-229.

Van den Akker, L., Heres, L., Lasthuizen, K. and Six, F. (2009), "Ethical leadership and trust: it's all about meeting expectations", International Journal of Leadership Studies, Vol. 5 No. 2, pp. 102-122.

Wong, C.A., Spence-Laschinger, H.K. and Cummings, G.G. (2010), "Authentic leadership and nurses' voice behaviour and perceptions of care quality", Journal of Nursing Management, Vol. 18 No. 8, pp. 889-900.

Yukl, G. (2013), Leadership in Organizations, Pearson, Upper Saddle River, NJ.

Yukl, G., Mahsud, R., Hassan, S. and Prussia, G.E. (2011), "An improved measure of ethical leadership", Journal of Leadership and Organizational Studies, Vol. 20 No. 10, pp. 1-11.

Zhu, W., May, D.R. and Avolio, B.J. (2004), "The impact of ethical leadership behaviour on employee outcomes: The role of psychological empowerment and authenticity", Journal of Leadership and Organizational Studies, Vol. 11 No. 1, pp. 16-26. 